\title{
BARCELONA 1854-1856: CRÓNICAS DEL ENSANCHE REFLEXIONES DE ANTONIO BRUSI FERRER
}

\section{BARCELONA. 1854-1856: CHRONICLES OF BARCELONA'S ENLARGEMENT: ANTONIO BRUSSI FERRER'S REFLECTIONS}

\author{
Mangiagalli, Sara Anna \\ Investigadora. Centro de Política del Suelo y valoraciones \\ Barcelona, España
}

Palabras Clave: Brusi, Diario de Barcelona, Ensanche, derribo de las murallas.

Palabras Clave: Brusi, Diario de Barcelona, city extension, demolition of the outer city walls.

Resumen: El artículo que aquí presentamos es fruto de una investigación que me ha permitido añadir un nuevo personaje al complejo marco político e intelectual de uno de los temas más determinantes para la historia de la ciudad de Barcelona: el derribo de sus murallas ${ }^{1}$.

Movidos por el interés de individuar las etapas fundamentales del que fue proyecto de desvinculación y venta de las murallas barcelonesas ${ }^{2}$, tras un estancamiento de nuestra investigación en la reconstrucción del proyecto financiero presentado por Pascual Madoz Ibáñez ${ }^{3}$, hemos querido focalizar este estudio en una revalorización de las observaciones

\footnotetext{
${ }^{1}$ El tema del derribo de las murallas de Barcelona ha sido tratado en la reciente exposición celebrada en en el Museo de História de la Ciudad de capital condal en el 2004: "ABAJO LAS MURALLAS!!! 150 anys de l'enderroc de les muralles de Barcelona.

${ }^{2}$ Citando las palabras del profesor Javier García-Bellido y García de Diego, director de este proyecto de investigación: "Habría que perseguir la pista de lo que pasó con este proyecto financiero de MADOZ, si creó la junta gestora, si se cubrieron o no los 20 millones, cómo, cuándo, etc., o si ni se llegó a subscribirse..." en MORALES \& GARCíA-BELLIDO \& Asís, eds. (2005): Pascual Madoz (1805-1870) Un político transformador del territorio. Homenaje en el bicentenario de su nacimiento, IPM-UCIII: Madrid,

${ }^{3}$ Los datos que hemos recuperado sobre el empréstito durante los seis meses que ha durado nuestra investigación han sido escasos. El vaciado del Diario de Barcelona nos ha proporcionado informaciones sobre el viaje de Madoz a Madrid para "[...] conferenciar con el gobierno acerca de los medios pecuniarios que deben arbitrarse para ir saliendo de la crítica situación en que se encuentra la capital del Principado. Exhausto completamente de fondos aquel ayuntamiento, ...y en la imposibilidad de adelantarlos el tesoro, han ofrecido al Sr. Madoz hacerlo alguno[s] capitalistas con la garantía de los terrenos que deja vacantes el derribo de las murallas.": DB: $n^{\circ} 282,11-O c t u b r e-1854$, p. 7.117, el informe de beneplácito de la reina al levantamiento del empréstito y el correspondiente proyecto autorizado: DB: $n^{\circ}$ 308, 5-Noviembre-1854, p. 7.769, los datos generales sobre la "Comision[sic] de la Junta creáda[sic] para la realización del empréstito de veinte millones de reales": DB: $n^{\circ} 315,13-N o v i e m b r e-1854$, p.7.980, el llamamiento a la participación al empréstito: DB: $n^{\circ} 326,23-N o v i e m b r e-1854$, p. 8.250 y por último los detalles sobre la sede de gestión del empréstito: DB: $\mathrm{n}^{\circ}$ 326, 23-Noviembre-1854, p. 8.251.
}

La falta de datos sobre la compra-venta de las cédulas emitidas para el cumplimiento del empréstito, tanto en el Diario de Barcelona como en las otras fuentes consultadas: Boletín oficial de la Provincia de Cataluña , El Centinela Barcelonés, El Constitucional, nos ha llevado a privilegiar un procedimiento de búsqueda de carácter más empírico.

Tras haber interpelado la historiadora Mercè Tatjer, experta en investigaciones de archivo y coautora junto a Marina López del inventario de las antiguas "Contadurías de Hipotecas", hemos intentado recuperar la fallida información a través de los datos contenidos en los antiguos "Libros de Oriente" (1861- ) del Distrito 1 del Registro de la Propiedad. Realizada una primera cata de fincas, edificadas entre 1864-1877 en los terrenos de las antiguas murallas: Calle Fontanella $n^{\circ} 13, n^{\circ} 15, n^{\circ} 17$, Ronda de Sant Pere $n^{\circ} 12, n^{\circ} 14, n^{\circ} 16$, Calle Trafalgar $n^{\circ} 31, n^{\circ} 33$, hemos intentado recuperar todo tipo de información que pudiera relacionarse, directa e indirectamente, al empréstito. El éxito negativo de la búsqueda nos ha llevado a considerar una nueva y ultima fuente documental: las "Contadurías de Hipotecas" de Barcelona (1768-1861). Como bien nos explican Marina López y Mercè Tatjer en Observasions sobre la historia de los Oficios de hipotecas en Cataluña (1768-1861), "Revista Crítica de Derecho Inmobiliario", Madrid, Any LX, gener-febrer 
divulgadas por el que fuera director del "brusi" sobre el ensanche barcelonés durante el "bienio liberal".

Guiados por la figura de Antonio Brusi Ferrer ${ }^{5}$, hemos engendrado nuestra investigación en un trabajo $^{6}$ atento en individuar los diferentes matices asumidos por el derribo de las murallas y el consiguiente discutidísimo ensanche de la capital condal en el Diario de Barcelona entre 1854 y 1856.

Summary: This article is the result of research that has allowed us to add a new figure to the complex political and intellectual framework of one of the most decisive aspects in the history of Barcelona: the demolition of the city's walls.

Moved by the interest to individualise the fundamental stages of what was the project of disconnexion and sale of Barcelona's walls, after a stagnation of our research in the reconstruction of the financial project presented by Pascual Madoz Ibáñez, we have wanted to focus this study on a revaluation of the observations published by the then director of the "brusi" concerning the enlargement of Barcelona during the "liberal biennium.

Guided by the figure of Antonio Brusi Ferrer, we have generated our research paying attention to individualising the different nuances shades assumed by the demolition of the walls and the subsequent widely-debated enlargement of the Catalonian Capital in the Diario de Barcelona between 1854 and 1856.

1984, núm.560, p. 131-150: “[...] els llibres de les comptadories d'hipoteques són uns veritables índexs dels protocols notarials, uns índexs elaborats per persones i per tipus de contractes." Siguiendo el inventario citado, orientándonos según las fechas de aprobación del empréstito: R.O. 6 de Octubre de 1854 y de las comunicaciones de la Comisión de empréstito: 23 de Noviembre de 1854, hasta el concluirse del bienio liberal, hemos visionado respectivamente los libros: 314: Cartas de pago: 11-11-1853/13-2-1855; 315: Cartas de pago: 14-2-1855/5-3-1856; 316: Cartas de pago: 53-1856/26-2-1857; 371: Barcelona 42: 30-6-1854/25-11-1854; 372: (Barcelona 43): 26-11-1853/9-2-1855; 373: Barcelona 44: 9-2-1855/7-5-1855; 374: Barcelona 45: 7-5-1855/4-9-1855; 375: Barcelona 46: 4-9-1855/7-1-1856; 374; 376: Barcelona 47: 7-1-1856/12-4-1856; 397: Barcelona 69: 9-10-1862/8-10-1862.

Fuentes de inestimable valor documental sobre las transacciones inmobiliarias, aún así, los libros de Contaduría no han aportado ningún dato de relieve para el objeto de nuestra investigación, dejándonos, una vez más, con la incógnita sobre el desarrollo del que fuera el proyecto financiero madociano.

Quedaría, entre otras más, la posibilidad de consultar los archivos notariales de la capital condal para aclararnos sobre el éxito del empréstito, siendo los notarios los personajes responsables de la gestión de las supuestas actas de compra de dichos terrenos, pero por motivos de tiempo, hemos preferido dejar este camino a otros investigadores del CPSV de la Universidad Politécnica de Cataluña.

${ }^{4}$ Así era como venía denominado cariñosamente por sus lectores el Diario de Barcelona.

${ }^{5}$ 1815-1878.

${ }^{6}$ Nuestra elección metodológica se ha basado en las pautas marcadas por Francisco Alía Miranda en op.cit p.326-327.: "[...] el manejo de la prensa como fuente implica conocer el contexto histórico de cada publicación. En resumen, establece como requisitos indispensables de método los siguientes:

1. Seleccionar las fuentes por medio de un conocimiento de la coyuntura histórica y de las publicaciones más importantes desde el punto de vista de su historia, de sus intereses económicos, políticos e ideológicos (historia de la prensa)

2. La consulta de varias publicaciones sobre el mismo tema y período estudiados (pluralidad)

3. Por último, no olvidar nunca, al utilizar esta fuente, que la prensa, además de información, opinión política, literatura o reportaje, es ideología."

El vaciado hecho sobre el Diario de Barcelona "De Avisos y Noticias", diario de tendencia conservadora, ha sido integrado con el de la fuente oficial Boletín oficial de la Provincia de Barcelona, analizada

enteramente entre 1854-1856, y las de El Constitucional "Periódico del Partido Liberal" y El Centinela Barcelonés "Periódico liberal independiente", fuentes progresistas analizadas de manera más puntual. 


\section{Introducción:}

Hijo de Antonio Brusi Mirabent ${ }^{7}$, Antonio Brusi Ferrer ${ }^{8}$, hasta el día de hoy personaje relegado al olvido en la cuestión del ensanche, puede definirse como una de las figuras más influyentes de la Barcelona de mediados del siglo XIX. Nombrado por el diplomático francés Ferdinand de Lesseps ${ }^{9}$, "[...] administrador de las acciones de la Compañía de Suez en la ciudad de Barcelona y, precisamente por ello, en toda España y miembro fundador del Consejo de administración de la Compañía" ${ }^{10}$, como nos dice el historiador Joaquín Álvarez Calvo: "gracias a él [Antonio Brusi Ferrer], debe, el Diario de Barcelona, la época más brillante, de más prosperidad, que, bajo su dirección alcanzó" ${ }^{11}$. Su notoriedad local y nacional culmina en 1875 con el otorgamiento, por parte del rey Alfonso XII, del título de Marqués de Casa-Brusi.

Empeñado, durante veintisiete años, ${ }^{12}$ en dirigir uno de los periódicos provinciales más importantes de la península, desde lo alto de su posición tanto de director del Diario de Barcelona como de ciudadano respetado, Brusi nos ofrece una imagen polifacética del complejo escenario barcelonés.

Seleccionados los artículos de fondo ${ }^{13}$ firmados por el director del diario catalán entre 1853 y 1855 podemos decir que la obra brusiana constituye "[...] una [valiosa] fuente para obtener información de acontecimientos, estados de opinión y mentalidad [de sus contemporáneos]."14 Inaugurada por Antonio Brusi la sección sobre las "Murallas de Barcelona" el 14 de mayo de 1853, con el evolucionar de las circunstancias, a este epígrafe se le sustituyen cronológicamente las de "Ensanche de Barcelona" y "Fortificaciones de Barcelona"15.

Es mediado de mayo de 1853 cuando el director del brusi escoge los recientes acontecimientos internacionales relatados en el Diario de Havre para dar inicio a la crónica de "un derribo

\footnotetext{
${ }^{7}$ Antonio Brusi i Mirabent, "Impresor y Librero", el día 6 de junio de 1814 obtiene la autorización por el General Copons a publicar el Diario de Barcelona, periódico fundado, editado y de propiedad de Don Pedro Pablo Usson de Lepazaran desde 6 de abril de 1792.

Con el fallecimiento de Antonio Brusi Mirabent en 1821, victima de la fiebre amarilla, la dirección del periódico pasa a Don Pablo Soler, quien mantendrá el cargo hasta 1838.

${ }^{8}$ Por comodidad, a lo largo de este elaborado, Antonio Brusi Ferrer vendrá indicado simplemente con el apellido de Brusi.

${ }_{9}^{9}$ El propulsor del canal de Suez, Ferdinand de Lesseps, hijo del diplomático francés Matthieu de Lesseps y de Catherine Grivégnée y Gallegos, tras su nombramiento el 27 de octubre de 1839 como Cónsul de primera clase en Málaga, en junio de 1842 obtiene el cargo de Cónsul de Francia en Barcelona, mandato que ejerce hasta abril de 1848 y que le permite conocer y establecer una profunda amistad con Antonio Brusi.

${ }_{10}$ Catalogo exposición: (2005) Ferdinand de Lesseps entre Terra i Mar, Yasmina Boudhar comis., Museum Marítim Drassanes Reials de Barcelona, Consulat Général de France à Bercelone, Asociación du Souvenir de Ferdinand de Lesseps, franc/cat/cast, Barcelona, p. 24.

${ }^{11}$ Joaquín Álvarez Calvo (1940): Historia del Diario de Barcelona 1792-1938, Barcelona, Imprenta LA NEOTIPIA, p.86. 12 1838-1875.

${ }^{13}$ Los artículos a los que se hace mención han sido catalogados siguiendo el orden cronológico de publicación: Antonio BRUSI [A.B.], "Murallas de Barcelona Conveniencia de su desaparición", en Diario de Barcelona [DB]: $n^{\circ}$ 134, 14-Mayo1853, p. 3.453; A.B., "Murallas de Barcelona Conveniencia de su desaparición Artículo II", en DB: $n^{\circ}$ 135, 15-Mayo1853, p. 3.480; A.B., "Murallas de Barcelona Ensanches que serían peores que el statu quo ¿Qué debe hacerse actualmente?", en DB: $n^{\circ}$ 282, 9-Octubre-1853, p. 7.172; A.B., "Murallas de Barcelona Estado presente de la cuestion[sic]" en DB: $n^{\circ}$ 35, 4-Febrero-1854, p. 851; A.B., "Ensanche de Barcelona ¿Qué debe hacerse ahora para resolver acertadamente la cuestion[sic]?" en DB: no 304, 1-Noviembre-1854, p. 7.759; A.B., "Ensanche de Barcelona Propiedad del terreno de las murallas Declaracion[sic] de plaza de guerra" en DB: $n^{\circ} 14$, 14-Enero-1855, p. 384; A.B., "Ensanche de Barcelona" en DB: $n^{\circ}$ 27, 27-Enero-1855, p. 783; Joan Mañé Flaquer [J.M.F.] "¿Barcelona debe ser plaza de guerra?" en DB: $n^{\circ} 37,6$-Febrero-1856, p. 1.066; J.M.F. "Ensanche de Barcelona" en DB: $n^{\circ}$ 60, 29-Febrero-1856, p. 1.751; J.M.F. "Fortificaciones de Barcelona" en DB, nº 69, 9-Marzo-1856, p. 2.019; J.M.F. "Ensanche de Barcelona II" en DB: $n^{\circ} 172,21-J u n i o-1857$, p. 5.053.

${ }^{14}$ ALÍA MIRANDA, F.: (2005) Técnicas de investigación para historiadores. Las fuentes de la historia, Editorial Síntesis: Madrid, Parte III: Fuentes y documentación, p.326.

${ }^{15}$ Esta última, en realidad, corresponde a Joan Mañé Flaquer [en castellano: Juan Mañé Flaquer], sexto director del Diario de Barcelona tras ser precedido en el cargo por: Pere Pau Usson (1792-1810), Manuel A.Igual (1810-1814), Antonio Brusi Mirabent (1814-1821), Pau Soler (1821-1838) y Antonio Brusi Ferrer (1838-1865), en HUERTAS J.M. (1992): 200 anys de premsa diaria a Catalunya 1792-1992, Fundaciò la Caixa de Catalunya, 543 p.; GUILLANT J. (2003): Els orígens de la premsa a Catalunya Catàleg de peròdics antics (1641-1833), Ajuntament de Barcelona, 436 p.
} 
anunciado": el de las murallas de la ciudad condal. Respaldado por los casos extranjeros de Havre, Tolon y Londres el caso de las fortificaciones barcelonesas parece no tener más una justificación ni histórica ni militar:

"[...]Hace tiempo que Barcelona conoce que las murallas no le permiten alcanzar el desarrollo á que se siente llamada, y en una de las explosiones [sic] que dio su máquina gubernativa, como un recurso para contentar la opinión pública, se apeló respecto de este punto al remedio heroico [sic] de cortar el nudo en lugar de desatarlo. El célebre comensem ha pasado á ser proverbial, pero después se ha levantado mas respetable de lo que era antes la ciudadela donde fue proferido aquel grito, quedando con todo sin reparar los considerables trozos de muralla que fueron derruidos en aquel entonces. Este es, pues, un problema que está aguardando la cabeza y la mano que lo resuelvan." ${ }^{16}$

Precedido, en la década de los cuarenta ${ }^{17}$, por los escritos de Monlau, Balmes y Figuerola relativos al caso de ensanche, Brusi no olvida citarlos, junto a sus obras ${ }^{18}$, en las premisas de sus reflexiones considerándolos el antecedente "teórico" de la futura Barcelona ensanchada.

Anclada a los hechos del 26 de octubre de 1841, fecha de inicio del derribo de las fortificaciones de la Ciudadela, reconstruidas súbitamente por orden de Espartero, la capital condal "encerrada en su estrecho circuito de piedra" parece no tener un porvenir en la rápida carrera que protagonizan las demás capitales europeas: Edimburgo, Liverpool, Hamburgo, Ámsterdam y Marsella. Emulando los casos citados, según Brusi, la nueva clave de éxito de la "segunda capital" de España ha de ser el "poder financiero":

"[...] La afluencia de capitales es el remedio único y natural para hacer frente á calamidades que se presentan de tanto bulto en el porvenir. Aquellos nunca van solos, sinó [sic] que llevan tras de sí la confianza, el crédito, el espíritu de vastas empresas, y todos los atributos del esplendido reinado que da la ley al mundo mercantil; empero es un hecho también cierto que los capitales no acuden sino allí donde hallan medios para extender [sic] sus operaciones los que los poseen y para disfrutar de las comodidades de la vida. Uno y otro efecto solo pueden procurarlos reunidos las grandes poblaciones con su expansión [sic] ya facilidad para el comercio, el desarrollo de mil florecientes industrias, y el aliciente de pasatiempos y goces refinados."19

Es decir, abandonar las fortificaciones continuas por una defensa puntual situada estratégicamente en las montañas y en la zona de mar, dejando a la ciudad un desarrollo de río a río, hacia las poblaciones de las vecinas montañas, y su consiguiente florecer industrial y comercial.

Las primeras reflexiones concluyen con la confirmación, por parte de su autor, de la decisión del Ayuntamiento de apoyar un "ensanche ilimitado", proyecto que como sabemos se remitirá a Madrid bajo informe el 24 de mayo de 1853.

\footnotetext{
${ }^{16}$ En DB: no $134,14-$ Mayo-1853, p. 3.453.

${ }^{17}$ En DB: no $134,14-$ Mayo-1853, p. 3.453.

18 ".... Para facilitarlo contribuiremos en lo que sea dable, añadiendo nuestras reflexiones á las que con tanto criterio avanzaron el señor Monlau en su Memoria premiada, el ilustre Balmes en los artículos escritos en la Sociedad, el señor Figuerola en su Estadistica, y varios otros escritores que no han verificado con mas ó menos detenimiento.", en DB: ${ }^{\circ}$ 134, 14-Mayo-1853, p. 3.453

${ }^{19}$ Monlau Felipe: (1841) ¡Abajo las murallas!!! Memoria de las ventajas que reportaría Barcelona, y en especialmente su industria, de la demolición de las murallas que circuyen la ciudad su autor Pedro Felipe: Barcelona, Imprenta del Constitucional.

Monlau Felipe: (1847) Elementos de higiene pública: Barcelona, Imprenta de Don Pablo Riera.

Figuerola Laureano: (1849) Estadistica de Barcelona en 1849, Barcelona, Imprenta y Librería Politécnica de Tomas Gorchs.

Por cuanto concierne los escritos de Balmes se remite al periódico Sociedad.
} 
Esbozados los principios de conveniencia del derribo de las murallas: higiene y desarrollo económico, el análisis se detiene en los transcursos políticos de la capital condal durante la década de las bullangas: 1833-1843:

"[...] Por lo dicho se ve que en las diferentes vicisitudes que corrió nuestra capital en aquella época de azares, las murallas no le fueron al gobierno de utilidad alguna, y nosotros creemos ser mas exactos asegurando que, sin ellas, las diferentes rebeliones ó no habrían [sic] tenido lugar, ó hubieran carecido de la importancia que adquirieron."

Según Brusi los acontecimientos europeos desenlazados alrededor del año '48, véase la independencia de Hungría bajo la figura de Kossuth o el caso griego, parecen avalar la posición de Barcelona ante el derribo de sus murallas y el consiguiente ensanche. Los progresos bélicos han superado las antiguas ciudades amuralladas y con ellos los últimos desórdenes populares que han invadido el continente europeo. El ejemplo a seguir es el escogido por Luís Napoleón para la capital francesa:

"[...] Con el ensanche se imposibilita para siempre todo disturbio semejante. Abramos una página [sic] del libro de Luis Napoleon [sic] y nos dirá que las anchas calles de 20, 24 y hasta 50 metros,-100,120 y 250 palmos catalanes- con que va á cruzar el centro de Paris, trasformándolo de un modo que no se creería sí en un año no hubiese llevado la portentosa calle de Rívoli desde las Tullerías al Hotel de Ville, no solo serán un embellecimiento y convertirán en foco de salud y vida lugares mefíticos, pasto en que se cebaban todas las epidemias, sino que el gobierno conseguirá con ellas quitar los recodos y tortuosidades desde donde cual en seguro baluarte eran diezmados sus soldados en los días de horror y luto provocados por intestinas discordias. Con la edificación de la nueva Barcelona, la antigua, por fuerza misma de vitalidad que adquiriría la circulación, vería dilatadas todas sus arterias principales, como lo ha sido en parte y va á serlo en otra la que recorre de N.E. á S.O., y acabaría de lograr el efecto que con esta en gran manera ha conseguido. "21

Destaca entre sus observaciones la que el Municipio promueva un concurso público para los contenidos del ensanche, concurso que tras cinco años de retrazo verá luz el 15 de abril de 1859 por mano de la Comisión Consultiva de Ensanche, es decir, cuatro días después del viaje emprendido por Ildefonso Cerdá, junto a Llasera ${ }^{22}$, rumbo a Madrid para presentar su proyecto final de ensanche.

El 9 de octubre de 1853, fecha en la que se publica el tercer artículo, la cuestión del ensanche, según las palabras del director, parece "sumergida en aparente letargo". Tras cuatro meses de participación e interés en el caso barcelonés por parte de su población, de sus periódicos, de las principales corporaciones y personas influyentes de la ciudad, entre los cuales es legítimo pensar el mismo Brusi, el complejo cuadro político español, regido por Sartorius, desfavorece, una vez más, el progreso de la capital condal y el tan esperado ensanche:

"[...] Diría se [sic] que fue aquello una favorable brisa que impulsó por algunos días la nave que encierra nuestros lares y nuestra fortuna, y que calmado el benéfico viento reinó de nuevo una bochornosa calma. Para desvanecer sus efectos, partieron hace poco nuevas exposiciones [sic], pero acaso no tuvieron tiempo para llegar á su destino, cuando habían bajado ya de los puestos que ocupaban los personajes á quienes iban dirigidas, sin que hubiesen tomado resolución

\footnotetext{
${ }^{20}$ En DB: no $135,15-M a y o-1853$, p. 3.480.

${ }^{21}$ En DB: no $135,15-$ Mayo-1853, p. 3.480.

22 Llasera Esteve, Gobernador civil de la provincia barcelonesa entre julio de 1855 y octubre de 1856, fue homenajeado el 13 de noviembre de 1856 con una medalla de oro, por parte de la Diputación, por su operado durante el cargo y por su apoyo al ensanche de Barcelona. 
alguna en este asunto. Si realmente tuvieron intención de llevarlo á cabo, mas de una vez les habrá de pesar en su retiro el haber dejado para otros mas afortunados la gloria imperecedera que han de reportar los que le den feliz terminación."23

El problema del ensanche asume en esta fase una nueva faceta, como bien lo sintetiza el mismo título del artículo: "Murallas de Barcelona. Ensanches que serian peores que el statu quo ¿Qué debe hacerse actualmente?"24, y tres las posibles respuestas ofrecidas por Brusi. La primera, sostenida por el mismo director, conforme a los deseos expresados por la ciudad y sus "órganos legítimos": un ensanche ilimitado, la segunda, basada en el mantenimiento del statu quo, lo que podríamos traducir en una "no decisión", finalmente, la tercera, un ensanche limitado y raquítico:

"[...] Si bien en la materia que nos ocupa no esperamos una resolución pronta, ni tememos una dilatación ilimitada, entra en la esfera de nuestros temores la posibilidad de que se resuelva de modo que resulte estéril y, como hemos dicho, infinitamente mas perniciosa que el presente statu quo."25

En unos tiempos en los que los gastos públicos representan un reto imposible a cumplirse por parte de la administración, como bien reconoce Brusi, el ensanche ilimitado aparece como el verdadero instrumento generador de riqueza pública, tanto para la misma ciudad como para el Estado.

Ensanches limitados, como el antiguo proyecto previsto a lo largo del paseo de Gracia, o el aún más dañino proyecto comprendido entre las huertas de San Beltrán y las faldas del Montjuich, representan, para la mayoría de la opinión pública, la peor amenaza para la capital condal. Así lo confirman las mismas palabras de Brusi:

"[...] Las voces que mas de una vez hemos oído desde que en mayo último se agitó la cuestión de las murallas, de que este plan [San Beltrán] tenia probabilidades de obtener la preferencia, son acaso lo que principalmente nos ha movido ahora a tomar nuevamente la pluma, porque no vacilamos en calificar este proyecto del arma mas perniciosa que en daño de la futura pujanza de Barcelona pudiera asestarle un cruel enemigo." 26

Nuevamente los referentes para la Barcelona ensanchada han de ser Marsella, Liverpool, Hamburgo, Génova y Nueva York: "principales exponentes [sic] de los adelantos de sus respectivas naciones".

Al proyecto de San Beltrán, engendrado en un trazado de "islas" y "manzanas" de casas para ochenta/noventa mil habitantes, Brusi contrapone la construcción de un nuevo muelle ${ }^{28}$ y espaciosos almacenes que permitan a la capital condal competir con ciudades mercantiles del calibro de Londres o Liverpool.

Sintetizando, los tiempos empiezan a presentarse maduros para que el problema del ensanche se exponga a través de un plan que ofrezca una solución, junto a la "Estadística"29 según nos

\footnotetext{
${ }^{23}$ En DB: no 282, 9-Octubre-1853, p. 7.172.

${ }^{24}$ En DB: no 282, 9-Octubre-1853, p. 7.172

${ }^{25}$ En DB: no 282, 9-Octubre-1853, p. 7.172.

${ }^{26}$ En DB: no 282, 9-Octubre-1853, p. 7.172.

${ }^{27}$ En DB: $n^{\circ} 282$, 9-Octubre-1853, p. 7.172.

${ }^{28}$ El tema del puerto de Barcelona es tratado repetidamente en los artículos del Diario de Barcelona del año 1856: Jorge Lasso de la Vega, en DB: $n^{\circ} 2$, 2-Enero-1856, p. 42; José Blay, en DB: nº 9, 9-Enero-1856, p. 231; José Blay, en DB: $n^{\circ}$ 90, 30-Marzo-1856, p. 2.589; "Puerto de Barcelona Dictamen de la comision [sic] y voto particular del señor Degollada para el ensanche, abrigo y mejora del puerto de Barcelona. Proyecto de ley" en DB: n 92, 1-Abril-1856, p. 2.641 ; C.A, en DB: $n^{\circ} 112,21-A b r i l-1856$, p. 3.257

${ }^{29}$ La disciplina estadística es repetidamente nombrada por Brusi como el instrumento indispensable para poder trazar el plano topográfico. Evidente es la referencia a las obras de Pascual Madoz y Laureano Figuerola.
} 
dice Brusi, a la cuestión general en su conjunto, tanto que venga del gobierno central como del Ayuntamiento.

El año 1854 se inaugura sin cambios significativos para la segunda capital de España.

Entre las síntesis de los temas ilustrados en los artículos anteriores Brusi nos ofrece los nombres de los diputados catalanes ${ }^{30}$ ocupados en solicitar al gobierno el urgente derribo de las murallas de tierra: expuesto del 18 de diciembre de 1853.

Haciéndose eco de cuanto escrito en un periódico inglés ${ }^{31}$, el caso de sitio de Amberes de $1831^{32}$ o la cuestión de Oriente son los nuevos ejemplos extranjeros que según el director reiteran la inutilidad de las fortificaciones.

En este artículo, sus atenciones parecen focalizarse en privilegiar la descripción de los beneficios bélicos para la capital condal con el inminente derribo:

"[...] Nos hemos detenido en estos pormenores porque, á nuestro entender el derribo de las murallas terrestres de Barcelona, tendría por efecto inmediato el aumentar su verdadera defensa, la defensa marítima. Por un lado ensanchándose

extraordinariamente el recinto, quedaría la mayoría de la ciudad fuera del tiro de cañón de las escuadras, y enlazada la cuestión del ensanche con la de construcción del puerto se proveería [sic] á su defensa con el levantamiento de baterías marítimas sólidas y bien artilladas." ${ }^{33}$

A principio de julio de 1854 los ánimos liberales empiezan a animarse por la península.

A la espera del comienzo del bienio liberal, inaugurado con la entrada de los generales Espartero y O'Donell el 29 de julio en Madrid, un nuevo actor aparece en la escena barcelonesa: la Academia de Medicina y Cirugía de Barcelona.

Como podemos aprender de las ediciones del 5 y 6 de julio, se publica el informe del cuerpo académico relativo a las influencias de las murallas en la salud del vecindario y de los resultados higiénicos que deben esperarse de una demolición completa de dichas fortificaciones. En nombre de "la comodidad, cultura y salubridad de una población importante" se reclama el derribo de las murallas, única salida para poder ofrecer a la ciudad anchas calles, jardines, plazas, mercados, parques y baños públicos.

A las condiciones topográficas ventajosas de la capital del Principado se contrapone el alto taso de mortalidad detectado en la misma entre el año 1849 y 1853.

A remarcar la posición defendida por la Academia se ofrecen los datos de las capitales europeas: Londres y Paris, comparándolos a los de la capital condal.

Tras el informe de la Academia de Medicina es la exposición ${ }^{34}$ para el derribo de las murallas del Ayuntamiento presentada a la Junta provisional de Cataluña a marcar una nueva etapa en el caso barcelonés.

Como bien aclara Javier García Bellido será esta misma "Estadística" a ser "una obsesión" para Ildefonso Cerdá, contemporáneo de Madoz, y conocedor de los trabajos de Francisco Coello de Portugal.

Citando las mismas palabras del mismo Cerdá: "[...]Preciso es por lo tanto, antes de intentar siquiera sentar las bases de una teoría urbana acometer un estudio especial, concreto, individual, si así cabe decirlo, de una urbe determinada, y poner además su parte material en paragon con el vencidario que contiene, y procurar por este medio comprender las relaciones intimas indisolubles, que entre y su contenido existen, á fin de juzgar con pleno conocimiento de causa si en esas correlaciones hay justa correspondencia, equidad y armonia, ó bien inclusas preponderancias, desequilibrio y desconcierto." En Javier García-Bellido y García de Diego, (2005): Ab modo de prólogo: Madoz en los albores de la política urbanística y territorial del siglo XIX, p.10: $\$ 16$.

${ }_{30}$ Pascual Madoz.-El marqués de Bedmar.- Juan Vilaregut.- Fernando Moragas y Ubach.- Francisco Puig.- Felipe de Martínez Davalillo.- Antonio Satorras y Vilanova.- José Ceriola.- José García Camps.- José Sol y Padrís.- Félix Ruiz de Fortuna.- Juan Agell.- Pedro Moret.- Angel de Villalobos.- Juan Bautista Clavé.- Jaime Ceriola y Flaquer.

${ }^{31}$ Cuyo título se omite.

${ }^{32}$ El tema del derribo de las fortificaciones de la ciudad de Amberes viene tratado detalladamente en el artículo de fondo de 1857 firmado por J.M y F [Joan Mañé y Flaquer], en DB: nº 172, 21-Junio-1857, p. 5.053.

${ }^{33}$ En DB: $n^{\circ} 35,4-F e b r e r o-1854$, p. 851.

${ }^{34}$ Dictamen favorable en fecha 25 de julio de 1854. 
Es interesante notar como en este ultimo expuesto a los beneficios higiénicos, tratados por la Academia, se les sustituyen los beneficios "productivos", es decir, la posibilidad de proporcionar, a través del derribo, trabajo a la clase jornalera, tema, por cierto tratado y resuelto por Pascual Madoz: "[...] se erige en impulsor del derribo combinándolo con el recurso suelo estatal y capitales privados para emplear a los obreros despedidos por las selfactinas en una conjunción inteligente de recursos y paro-desarrollo-crecimiento, en una misma operación de inversión publico-privada y empleo cuyos plus valores crean más capital e inversión, etc."35 Utilizando las mismas palabras de la editorial del 21 de julio:

"El Excmo. Ayuntamiento constitucional en sesión extraordinaria celebrada en el día de ayer, votó una exposición pidiendo á la Junta provisional de Cataluña el derribo de las murallas de Barcelona, y que esta medida se acuerde desde luego

para facilitar trabajo á los numerosos brazos que carecen de medios para procurarse el sustento.

[...]La terminación del ferro-carril de Granollers, lo adelantado del de Martorell, sin que por ahora se trate seriamente de emprender ninguna otra línea; las muchas personas quedaran sin ocupación de resultas de recientes y dolorosos sucesos; el triste y desconsolador aspecto de la más importante cosecha del país; el estado muy avanzado de la mayor parte de las obras públicas emprendidas en esta ciudad, y la imposibilidad de inaugurar otras útiles y grandiosas en su actual recinto, todas estas razones y otras que podríamos agrupar, nos indican lo acertada que ha estado la Excma. Corporación municipal en presentar como urgente la medida, y creemos que las mismas razones pesarán en el ánimo de la Excma. Junta provisional para resolver que sea llevada á cabo sin tardanza.

Una reflexión tan solo añadiremos de mucha valía para todo hombre pensador, referente á un hecho que está pasando á nuestra vista, y es que en el grande desarrollo que el Emperador Napoleón ha dado á las obras públicas del imperio se funda una de las causas principales que han influido en su sosiego, en el crecimiento de su riqueza, en el desarrollo de su fuerza nacional, en la expansión [sic] de su comercio é industria y en los progresos de su agricultura. Iguales resultados tendrá, á no dudarlo, el ensanche total de Barcelona si es llevado á cabo con toda grandiosidad de miras que se merece, no solo por los inmensos capitales que pondrá en circulación, sino por las consecuencias indirectas y de incalculables beneficios que irremisiblemente en el adelanto general de la nación." ${ }^{36}$

Una vez más, para Brusi, es la figura de Napoleón III y el caso francés a marcar las pautas para la Barcelona moderna.

Los acontecimientos de la primera semana del mes de agosto de 1854 marcan el inicio del "cambio" que inaugurará el bienio liberal.

El nombramiento de Domingo Dulce como capitán general de la provincia catalana, en sustitución de Ramón de La Rocha, conjuntamente al de Pascual Madoz en calidad de Gobernador civil de la ciudad barcelonesa, marcan la apertura física y política de la ciudad amurallada hacia el ensanche.

La dura situación económica, unida a la surgente epidemia de cólera, actúan de manera sinérgica hacia la nueva política liberal engendrada en la resolución afirmativa del Consejo de Ministros sobre el derribo de las murallas barcelonesas: 12 de agosto de $1854,{ }^{37}$ y tras diez

\footnotetext{
${ }^{35}$ Javier García-Bellido en Prolegómeno: Madoz en los albores de la política urbanística y territorial del siglo XIX» en MORALES \& GARCÍA-BELLIDO \& ASÍS, eds. 2005: Pascual Madoz (1805-1870) Un político transformador del territorio. Homenaje en el bicentenario de su nacimiento: 19-50, IPM-UCIII Madrid.

${ }^{36}$ En DB: n 202, 21-Julio-1854, p. 5.207.

37 Se comunica al Capitán general Domingo Dulce, por parte del ministro de la Guerra, en fecha 12 de agosto, la resolución del Consejo de Ministros sobre el derribo de las murallas de Barcelona: "(...) $1^{\circ}$ Las murallas de Barcelona
} 
años el tan esperado levantamiento del estado de sitio en las cuatro provincias catalanas: 17 de agosto de $1854 .^{38}$

Inaugurado el derribo de las puertas de la ciudad y la apertura de los primeros boquetes, nombrados el director y los arquitectos auxiliares de la obra: el arquitecto municipal José Fontseré y los arquitectos Francisco Daniel Molina, José Oriol Mestres, Miguel Garriga, José Buxareu, obtenido el beneplácito de la reina al levantamiento del empréstito presentado por Pascual Madoz para la ciudad condal ${ }^{39}$, un nuevo tema protagoniza los artículos brusianos: el Ensanche de Barcelona.

Brusi se detiene en explicar las motivaciones, del Ayuntamiento y de la "Comisión de ensanche", en no querer elaborar un plano general hasta estas mismas fechas por miedo de favorecer un fenómeno especulativo:

"[...] que al acordarse en las sesiones del 19 y 24 de enero celebradas por la comisión especial, lo que después aprobó S.E., que los arquitectos del ayuntamiento D.Jaime Mas, D.Daniel Molina, D.Juan Soler y Mestres, D.J. O. Mestres y D. José Fontseré, levantaran el plano que en aquella exposición se ofreció al gobierno, dispuso se [sic] que no se trazase ninguna calle ni edificio en el terreno de la fortificación y de la zona militar, llenándose ya sin ello el objeto de la formación del plano, que era manifestar al gobierno la imposibilidad de todo ensanche parcial, puesto que estaban casi tocando las murallas de la ciudad Hostafranchs y Sans á un lado, Gracia al otro y mas allá San Martin de Provensals y el Pueblo Nuevo, de modo, que en caso de ser sitiada por un ejército extranjero [sic] se vería obligada á rendirse pronto al enemigo desde la nueva plaza fuerte en que sus alrededores estarían convertidos." ${ }^{40}$

El camino indicado por Brusi es la elaboración de un "plano topográfico completo" y la "formulación de un proyecto rentístico" para poder cubrir los gastos del ensanche.

Queda a resolver uno de los temas más conflictivos: la propiedad de los terrenos resultantes del derribo de las murallas, fosos y glacis, una propiedad disputada entre el Municipio, el

que miran á la parte de tierra,...serán demolidas bajo las superiores órdenes de $V$.E,...teniendo en la operación el cuerpo de Ingenieros y la Administración militar la parte que respectivamente les compete según sus atribuciones. $2^{\circ}$ Se podrán en venta los terrenos sobre los cuales se hallan asentadas las fortificaciones, y su producto..., sirviendo desde luego, en la parte necesaria, para sufragar el coste del derribo. Al propio tiempo ha tenido á bien S.M. declarar que se reserva resolver si Barcelona ha de seguir figurando en el sistema defensivo del reino como plaza fuerte y en que categoría.", en DB: n² 228, 12_Agosto-1854, p. 5.896.

${ }^{38}$ "El General Dulce, fiel á sus convicciones, proclama en alta voz el imperio de la ley en las cuatro provincias de Cataluña. El estado de sitio se levanta desde este día. Cuando yo en el Parlamento he defendido esta medida, que la opinión pública reclamaba, y la observancia estricta de la Constitución exigia, podéis figuraros si será grande mi satisfaccion en este momento. Una legislacion que cuenta la Pragmática de Carlos III, que es la ley 5.tit.11.lib.12 de la Novísima Recopilacion; una legislacion que contiene las leyes de 17 de abril de 1821, restablecidas en 30 de Agosto de 1836, no necesita esa ficcion del estado de sitio, á cuya sombra se han cometido todo género de tropelias; la Constitucion de hoy en adelante ha de ser una verdad; y los pueblos deben adquirir el hábito de respetarla y sostenerla; el Capitan General tiene confianza en vosotros. Seguro estoy que no verá defraudadas sus esperanzas; con un Gobierno que proclamando la libertad de eleccion, confía al Parlamento los destinos de la Patria; con Diputaciones y ayuntamientos que representen la verdadera opinion pública, libre de toda coaccion, de toda sugestión, de toda intriga; con la Milicia Nacional, garantia a la vez de libertad y órden público, debemos tranquilos esperar la marcha ordinaria de los sucesos, y prepararnos con confianza á la lucha legal de todos los diferentes actos electorales; la época para la provincia de Barcelona es de prueba. Pero con la confianza que debe existir entre el pueblo y las Autoridades, y la cooperación franca y decidida del Ejército, venceremos cuantos obstáculos se presenten, y sacaremos ileso el depósito de las libertades públicas; la provincia de Barcelona agradecida, saluda á su nuevo Capitan General D.Domingo Dulce.", en Boletín oficial de la Provincia de Cataluña [BOP]: nº 117, 17-Agosto-1854, p. 1. ${ }^{39}$ Real Orden 6 de octubre de 1854.

${ }^{40}$ En DB: $n^{\circ} 304,1-N o v i e m b r e-1854$, p. 7.559. 
Ministerio de Guerra y por último por la misma Isabel II según las últimas investigaciones avanzadas por Javier García Bellido y expuestas en el "IX Congrés d'Història de Barcelona". Comparando una vez más el caso barcelonés al parisino el director del brusi observa:

"[...] dudamos de que sea suficiente para este objeto todo lo que se pueda enajenar [sic] de aquellos terrenos, opinando por el contrario que á mas del canon [sic] que de común acuerdo se imponga á los particulares, tendrá la Corporación municipal que hacer alguna demanda al Gobierno Superior para hacer frente á los infinitos objetos á que deberá atender para llenar cuantas exigencias tienen las grandes poblaciones modernas. La concesión hecha por el gobierno francés para la pronta terminación de la famosa calle de Rivolí de París podrá tal vez servir de un útil precedente [sic].

Con lo que llevamos expuesto [sic], creemos ya rebatida la condición del mencionado proyecto de empréstito que dice que «para mayor garantía y estimación [sic] de los solares que resulten de dicho derribo (el de las murallas), el gobierno asegura y concede desde ahora la facultad de edificar á toda la altura permitida por los bandos municipales pero únicamente en los terrenos resultantes del derribo de las murallas, fosos y glacis que son de su propiedad.»

En esta condición solo sabemos ver un exceso [sic] de celo y de buena voluntad en el gobierno para garantizar el empréstito, pero que perjudicaría visiblemente esta misma operación, pues los terrenos comprendidos en los fosos y murallas adquirirán mas valor cuanto mas céntricos los hagan los nuevos edificios que se levanten. Además de esto, no atinamos á discurrir qué seria el ensanche de Barcelona si tuviese que quedar reducido á edificarse nuevamente tan solo en aquel reducido espacio. Imagínense todas las combinaciones posibles y ninguna se encontrará mas incalificable que ese non plus ultra que tendrían la fuerza de imponer las antiguas murallas con sus efectos de ultra tumba. $[\ldots]^{, 42}$

Tras las conclusiones del año'54 Brusi publica un nuevo artículo engendrado en unas duras críticas a la gestión de los últimos meses del ensanche. El tema de la propiedad de las murallas, junto a la condición de plaza de guerra, protagoniza el primer artículo de 1855:

"[...]Nos han confirmado en la creencia de que se da [sic] el punto como resuelto los trabajos que en estos últimos días hemos visto emprendidos en el foso del fuerte de Atarazanas que mira á las huertas de San Beltran y los que se hacen en el semiderruido baluarte del mediodía.

No solo presuponen estos trabajos que queda hecha la declaración de plaza de guerra, sino también, y lo que es mas, que se ha aprobado ya el plano que ha de tener esta plaza. Si así no fuese ¿á que vendría invertir sumas que luego serian infructuosas, según el proyecto que se adoptase? En este caso se encuentran las que se gastan en la parte de Atarazanas que mira á las huertas de San Beltran, siendo muy posible que se crea conveniente construir allí la nueva Aduana, y que las baterías se hallen mejor situadas á la entrada del nuevo puerto.

Por desgracia, si nuestras noticias son exactas, caso de que no haya llegado oficialmente la declaración de plaza de guerra, se halla esto muy próximo á verificarse, y con ellas va envuelto el declarar que no pueda edificarse á 1500 varas de la Ciudadella [sic], á otras tantas del Fuerte-Pio, á no sabemos cuantas de Atarazanas, el levantamiento de una cortina ó muralla, que bajando de Monjuich, y pasando por la Cruz Cubierta, vaya á encontrar el fuerte que hay levantado al lado del llamado ostentosamente del marqués de la Mina. Es regular que levantándose los nuevos fuertes y la nueva muralla se exigiría también que en las 1500 varas de la misma no

${ }^{41}$ IX Congrés d'Història de Barcelona: El tombant de 1868-1874, celebrado en el Arxiu Històric de la Ciutat de Barcelona los días 29-30 de noviembre y 1 de diciembre de 2005.

${ }^{42}$ En DB: n $^{\circ} 304,1-$ Noviembre-1854, p. 7.559. 
pudiese edificarse, resultando de ello, entre otros conflictos, que ó bien se irrogarían grandes perjuicios á los dueños de aquellos terrenos á quienes se privaría injustamente de edificar, ó subiría la indemnización de daños á sumas fabulosas." ${ }^{43}$

A los cuatro meses del último artículo, cumpliéndose los deseos expresados por el director, el Ayuntamiento Constitucional nombra una comisión ${ }^{44}$ para elaborar un expuesto a la reina en reclamación del dominio de los terrenos de las murallas.

Pocos días después se publican en el brusi los contenidos de la primera reunión de la "Comisión de ensanche".

En calidad de testigo Antonio Brusi nos informa tanto de los contenidos como de la identidad de sus participantes. ${ }^{45}$

Las tensiones obreras, junto a las amenazas carlistas, generan nuevos desordenes en el territorio catalán. Declarado el "estado de guerra" en la provincia barcelonesa por parte del Capitán General Zapatero el 28 de mayo de 1855, el gobernador civil Cirilo Franquet,

siguiendo el ejemplo de su predecesor Pascual Madoz, reitera la Real Orden del 9 de agosto de 1854 quedando sin efecto cualquiera disposición "(...) que las autoridades de esa capital hubiesen dictado sobre la tasa de salarios ó de la mano de obra de los trabajadores de esas fábricas, sin la previa y espontánea aquiescencia de los mismos obreros y fabricantes, cuya industria y trabajo deben ser completamente libres y arreglados los precios y condiciones de sus convenios por mutuo consentimiento y sin mas que atemperarse las leyes vigentes y autorizar la libre contratación[sic]". ${ }^{46}$

Es el mismo Madoz, bajo el nuevo cargo de Ministro de Hacienda, a animar el escenario político proponiendo una le ${ }^{47}$ de desamortización de bienes nacionales para sanear las cuentas públicas del país.

\footnotetext{
${ }^{43}$ En DB: n² 27, 27-Enero-1855, p. 783.

44 "Sabemos que el Excmo. Ayuntamiento Constitucional de esta ciudad ha nombrado una comision compuesta de los distinguidos letrados D. Pablo Valls, D. José Maria Pera, Don Francisco Permanyer y D. Manuel Duran y Bas, para que redacten una exposición á S.M. en reclamacion del dominio que, según creemos, tiene el municipio de Barcelona sobre el terreno de las murallas cuya demolición se está verificando." En DB: no 130, 10-Mayo-1855, p.3.819.

45“"...] el señor D. Ildefonso Cerdá, encargado por aquella superior autoridad del levantamiento del plano topográfico de los afuras [sic] de Barcelona, el señor Don Juan Merlo, ingeniero civil, jefe del distrito, el señor D. Simon Ferrer, jefe del ramo de marina, varios comisionados de la Diputación provincial, Ayuntamiento de esta ciudad, Junta de Comercio, Junta de fábricas, Sociedad Económica de amigos del Pais, Academias de Medicina y Cirugía y de Bellas artes, propietarios de terrenos de extramuros, y alguna otra corporación que no recordamos, y los Directores de periódicos de esta capital."en DB: no 163, 25-Mayo-1855, p. 4.167.

${ }^{46}$ En BOP: $n^{\circ} 68,6-J u n i o-1855$, p. 1.

${ }^{47}$ Ley de Desamortización del $1^{\circ}$ de mayo de 1855.
} 
Nombrado hijo adoptivo de la ciudad conda $^{48}$ en octubre de 1854, Madoz representa uno de los personajes más apreciados por la población barcelonesa. Gobernador civil en 1854 durante la devastadora epidemia de cólera, propulsor del derribo de las murallas en su triple faceta de particular, deputado y gobernador, sea talvez su apertura hacia las peticiones del Municipio barcelonés a mediados de los años cuarenta a otorgarle el respeto y la fama entre los barceloneses.

Ocupado desde 1834-1835 en preparar el Diccionario Geográfico-Estadístico-Histórico de España y sus posesiones de Ultramar, es a partir de 1846, con el envío al Municipio barcelonés de una comunicación sobre los contenidos de dicho diccionario, que una "comisión especial compuesta del seno municipal y de varias corporaciones científicas, [medita] ha meditado detenidamente sobre las importantes y necesarias mejoras que deberian hacerse en esta capital y sus inmediaciones para que con los elementos que encierra en el dia pudiese elevarse al rango de las primeras capitales de Europa; siendo las de mas influencia las siguientes" ${ }^{\prime 49}$.

Los once puntos expuestos en el primer borrador son:

1. a La rectificación del álveo del rio Llobregát [sic], cuyas arenas siegan la entrada al puerto formando una barra en esa boca.

2. a Un puente sobre el rio Besós que con sus avenidas [? $]^{50}$ Intercepta con frecuencia la comunicación con la costa de levante y vecino reino de Francia.

3. a La conclusión y conservación del puerto en el que apenas pueden entrar los buques de guerra, por la poca profundidad.

4. ${ }^{a}$ El ensanche de sus murallas, por el mucho aumento que ha tenido la población, por la mucha elevación que ha tenido que darse á los edificios á causa de no quedar

\footnotetext{
48 "Excmo. S or. Cuando Barcelona aterrorizada por los estragos del colera, y huerfana de un sin numero de familias que antes le habian dado vida y animación, veia diezmar por aquel terrible brote á su desagraciados hijos: mientras la miseria con su funesto cortejo de lágrimas y de luto penetraba en la vivienda del infeliz operario que no sabia como alargar [?] un pedazo de pan á su familia; cuando en fin la antigua Ciudad de los Condes, antes tan floreciente, veia con espanto cerrados sus talleres, casi desiertas sus calles, á causa de una desconsoladora emigración, y á sus infortunados hijos con una mano levantada hácia [sic] el Cielo en señal de súplica, y con la otra recibiendo, lleno de gratitud el corazon, el sustento que le alargaba el amor paternal de sus representantes en el Municipio, un Angel tutelar apareciò [sic] entre nosotros que, como enviado de lo alto, venia á enjugar nuestro llanto y á devolver á nuestro espíritu una gran parte de la calma de que tanto necesitabamos en nuestra angustiosa situación=Podria Barcelona, $\mathrm{S}$ or. Excmo., olvidar en ningun tiempo esos terribles dias y esas crueles noches en que con abnegación sublime y con celo verdaderam te. [sic] evangélico, salia S.E. al encuentro con la muerte disputarle sus victimas, arrancando no pocas de su poder y restituyendolas á las desoladas familias por medio de rapidas y acertadas providencias [?]=Testigo este Ayuntam to. De los esfuerzos heroicos, de los sacrificios sin cuento que S.E. tiene hechos en fabos [?] de esta Ciudad [?], tanto en la cuestión sanitaria, como en la industrial, en la politica y en cuantas, para bien de sus moradores de tres meses á esta parte, se han suscitado; admirador ademàs [sic] de las muy acreditadas virtudes cívicas que tanto enaltecen á la persona de S.E.; deseoso, no de envolver entre los perfumes de la lisonja á un idolo que no sabria adorar si fuera falso, sino de rendir á su ilustre y benefico protector; el tributo de su sincero agradecimiento, acordò por unanimidad, en sesion del 30 del pp do. mes, adoptar al Excmo. S or. D. Pascual Madoz por hijo de Barcelona, y que su esclarecido nombre, grabado con una inscripción propia de las circunstacias en una lápida de mármol á espesas de todos los individuos que forman hoy dia esta Municipalidad, figure en el Salon del Consistorio para que se conserve perpetuamente la memoria de S.E.=Humilde es la ofrenda $S$ or. Excmo., muy inferior sin duda á los merecimientos de S.E., pero es ofrenda que nace del corazon, y S.E. no podrà [sic] rehusarla. Acéptala, pues como un testimonio de la gratitud de este Ayuntamiento Consistorial, y yà [sic] que el destino de esta provincia es de verse privado, dentro de poco tiempo de la persona de S.E, tan respetada, tan señaladam te. Estimada de todos los habitantes de esta Ciudad [?] y de la provincia de toda, dignese S.E recibir estos momentos solemnes nuestro cordial saludo, no dudando que en cualquier parte donde S.E. se halle, le acompañaran las bendiciones del pueblo de Barcelona.": En Arxiu Administratiu: Año: 1854; Sección 2. ${ }^{a}$ Exp. 3.004; Comissió de Gobernació; Serie A: "Adopción del Excmo. Sr. D. Pascual Madoz, gobernador de la provincia, como hijo de Barcelona".

${ }^{49}$ Arxiu Administratiu: Año: 1854; Sección 2. ${ }^{a}$ Exp. 3.004; Comissió de Gobernació; Serie A: "Comisión especial".

${ }^{50}$ Con esta simbología hemos querido indicar nuestras dudas sobre la exactitud de la palabra transcripta siendo la fuente originaria un documento manuscrito. 
ya terreno para edificar, siendo la falta de ventilación otra de las causas que con mas urgencia lo reclaman.

5. a El establecimiento de escuelas de noche y de domingo para los que se dedican al trabajo durante el día.

6. a Una cátedra de Mecánica práctica.

7. ${ }^{\text {a }}$ Otra de Geometría descriptiva

8. a La formación de un código rural y creación de un cuerpo de guardias rurales para seguridad de la clase agrícola.

9. a Un aumento de escuelas de instrucción primaria atendido el aumento de la población

10. a Una casa de corrección para delitos leves particularmente de mujeres [sic], para que puedan estar separadas las que están connaturalizadas con el crimen de las que por primera vez sufren aquel castigo.

11. a La traslación de la casa de locos fuera de la Ciudad para que puedan ser curados según lo requiera la naturaleza de su enfermedad. ${ }^{51}$

La versión oficial, reducida a nueve puntos, sustituye directamente el ensanchamiento de las murallas con el derribo de las fortificaciones de tierra, postura que ya en estos primeros años Madoz apoya incluyéndola sin alguna modificación, junto a los otros ocho puntos, en la parte correspondiente a la ciudad condal de su Diccionario, acto, este último, que le permite, en nuestra opinión, conquistar la confianza y el aprecio de sus "conciudadanos" hasta los últimos años de su vida.

Abandonado el cargo de Gobernador civil por parte de Cirilo Franquet, el día 13 de julio de 1855, es otro personaje, Ignacio Llasera y Esteve, a tomar el mando de la frágil cuestión barcelonesa.

Tras meses de medido silencio el binomio Brusi-ensanche aparece por primera vez en las páginas del periódico El Constitucional bajo el epígrafe "El ensanche".

Remarcando el papel clave jugado por el director del brusi en tal tema, la editorial del periódico progresista se detiene en las observaciones, compartidas, firmadas por A.B. ${ }^{52}$ en las que se exige una pronta ejecución del ensanche.

Como bien se sintetiza en el artículo, la prioridad de un estudio topográfico detallado de los terrenos limítrofes a la ciudad amurallada, desacredita, en la lectura efectuada por sus contemporáneos, los temas tratados por la Comisión, ocupada, al contrario, en decretar aspectos del futuro ensanche cuales: "Reglas para la situación de establecimientos peligrosos [sic], insalubres é incómodos" o "Designación del punto de desagüe de los riegos inmediatos". No faltan en las palabras recogidas por El Constitucional la importancia de un ensanche cuya mejora pública no recaiga en monopolios particulares o en mera especulación de interés privado. ${ }^{54}$

En estas fechas los ataques cruzados entre los mayores periódicos, desde sus diferentes posturas políticas: conservadora y progresista, desvelan las primeras tensiones locales que condicionarán el desarrollo del ensanche barcelonés.

Encarados el Diario de Barcelona y El Constitucional por un lado y El Centinela barcelonés por el otro, sobre los tiempos de elaboración del plano topográfico de los terrenos de los alrededores de la ciudad, se critica por parte del segundo el trabajo de Ildefonso Cerdá: "ex ingeniero civil ${ }^{\prime 55}$ y su supuesta amistad con el ex Gobernador civil Cirilo Franquet.

\footnotetext{
${ }^{51}$ Arxiu Administratiu: Año: 1854; Sección 2. ${ }^{a}$ Exp. 3.004; Comissió de Gobernació; Serie A: "Comisión especial".

52 Antonio Brusi

${ }^{53}$ En Constitucional: $n^{\circ} 726,4-O c t u b r e-1855$, p. 1.

${ }^{54}$ En Constitucional: $n^{\circ} 726,4-O c t u b r e-1855$, p. 1.

${ }^{55}$ En El Centinela barcelonés: n $31,4-$ Octubre-1855, p. 4.
} 
A las inmediatas replicas cerdianas, publicadas como "cartas al director" en el Diario de Barcelona, sigue la visita del mismo Brusi al despacho de Cerdá para comprobar los avances de los trabajos preparatorios de ensanche:

“... [Se] confirma el estado adelantado de los planos respecto a los presentados a la Junta convocada por el Gobernador civil Cirilo Franquet a mediados de junio último. El plano incluye las poblaciones de los alrededores: de Sans hasta Pueblo Nuevo. Se resuelven los problemas de desviación de las aguas de la Riera de San Gervasio y del torrente de la Olla. Se han fijado los puntos cardinales de la ciudad actual para que puedan armonizarse con los de la nueva población al formarse el plan general. ${ }^{.56}$

El apoyo expresado al trabajo de Cerdá causa un duro ataque por parte de El Centinela barcelonés desvelando, desde estas fechas, la postura hostil por parte de algunas facciones al autor de la "Teoría General de la Urbanización".

Sin poder confirmar o desmentir desde nuestra posición cuanto expresado por el periódico progresista, creemos de gran interés, para una mayor claridad en la lectura de los acontecimientos del pre-ensanche, proponer las acusas publicadas contra la persona de Brusi, es decir, interpretar su defensa del trabajo cerdiano, según los ambientes más progresistas, como indicador de un interés personal por la plusvalía generada en los terrenos de las afueras de la ciudad por el trazado cerdiano de nueva población.

Concluido el trazado cerdiano, quedando aún pendiente el aspecto de "plaza de guerra", el proyecto de ensanche es nuevamente impulsado por el Ayuntamiento constitucional y el Alcalde Don José Maria Freixas.

En esta nueva operación el diputado catalán Francisco Camprodon, como se constata en las actas del congreso publicadas en los periódicos de la época, representa una de las figuras claves para la aprobación y el pronto cumplimiento del ensanche en el menos favorable gobierno central.

El 10 de enero de 1856, tras un año desde el derribo de las ya ruinosas murallas, el Ayuntamiento barcelonés se dirige a Isabel II para el levantamiento de un nuevo empréstito de diez millones de reales:

"(...) al objeto de poderse principiar con su producto los trabajos de ensanche, abriéndose al efecto cuatro grandes vías: $1 .{ }^{a}$ Desde el extremo [sic] de la calle Conde de Asalto hasta la Cruz Cubierta. 2. ${ }^{a}$ Desde el extremo [sic] de la Rambla hasta S. Gervasio. 3. ${ }^{\circ}$ Desde el extremo [sic] de la calle Princesa, hasta S. Andrés de Palomar. Y 4. ${ }^{a}$ Desde la Cruz Cubierta al que fue Baluarte de Hostafrancs, prolongándose la según la misma dirección hasta el rio Besós". ${ }^{57}$

Los nuevos desórdenes generados por algunos milicianos en seno al Congreso, junto a la crítica situación económica catalana, vinculada a la inminente ley arancelaria, parecen desplazar, una vez más, el tema de ensanche en segundo plano.

Es la noticia del viaje a Madrid de los concejales Admirall y Cerdá a alimentar el optimismo por un inminente ensanche:

"«Ha regresado á esta ciudad D.Cayetano Admirall, quien junto con D. Ildefonso Cerdá, ambos concejales, fueron en comision á Madrid para la cuestión de ensanche. Según hemos podido entender, la petición y proyecto de ensanche de esta capital fue bien acogida por el gobierno; y muy eficazmente secundada y apoyada con especial

\footnotetext{
${ }^{56}$ En DB: $n^{\circ} 283,10-O c t u b r e-1855$, p. 8.056

${ }^{57}$ En DB: ${ }^{\circ} 10,10-$ Enero-1856, p. 270.
} 
empeño por los señores diputados Madoz, Franquet y Camprodon. Se espera que recaerá pronto una favorable resolución, como la deseamos; y que sea sin gravámenes, ni impuestos, ni empréstito, ni cosa semejante. Un bien positivo como el ensanche, para que sea bien no ha de ser á condición de un mal, como seria un impuesto bajo cualquiera denominación.»" ${ }^{\text {58 }}$

Precedido por Antonio Brusi en los años 1853-1855, a partir de febrero de 1856, es el intelectual Juan Mañé y Flaquer a protagonizar con sus artículos de fondo las páginas del Diario de Barcelona.

Como bien ejemplifica el titulo escogido por su autor, el nuevo tema tratado es el binomio "Barcelona - plaza de guerra": ¿Barcelona debe ser plaza de guerra? ${ }^{59}$

La inexistencia de una línea de defensa a nivel nacional, según J.M.F [Juan Mañé y Flaquer], excluye la posibilidad de incluir Barcelona entre las plazas de guerra, definiéndola por el contrario como un "depósito de los ejércitos de mar y de tierra". 60

Las informaciones que llegan en estas mismas fechas desde Madrid, firmadas por M. [?] ${ }^{61}$ en las páginas del brusi, parecen no aclarar la posición del gobierno sobre este último aspecto, acusándose una vez más el Ministerio de Guerra como el responsable, incompetente, de dicha demora. ${ }^{62}$

Se confirma la necesidad de emprender lo antes posible las obras de ensanche, aún así, desde Madrid quedan a definir aspectos tan significativos como el de la designación del responsable de costear los gastos de las primeras vías del ensanche.

El corresponsal madrileño así nos sintetiza las modalidades expresadas por la Junta para la ejecución del ensanche condal:

"[...]En cuanto al modo con que debería verificarse el ensanche, considera la Junta que debería hacerse tomando por tipo el lugar y aire que se necesita por individuo para vivir cómodamente, y multiplicándolo por el número de habitantes que hoy tiene, mas lo que en el transcurso de un siglo debe aumentar, según la proporción creciente de estos últimos años y establecer un rádio [sic] que contenga el número de casas que resulten necesarias, lo cual, á nuestro juicio, importaría una extensión [sic] igual á la que hoy ocupa el llano de Barcelona." ${ }^{63}$

Unas nuevas discusiones sobre la apertura de cuatro grandes vías, previstas en el anteproyecto cerdiano, inauguran las reuniones primaverales de la Comisión de ensanche:

"[...] es preciso que entere á Vds. que las cuatro vías que solicita abrir el Ayuntamiento, son con arreglo á un anteproyecto trazado por el ingeniero Cerdá de latitud unos cincuenta metros, designándose en ellas lugar para las vías férreas, carruajes, gente

\footnotetext{
${ }^{58}$ En DB: n² 21, 21-Enero-1856, p. 622.

${ }^{59}$ En DB: $n^{\circ} 37,6-F e b r e r o-1856$, p. 1.066.

${ }^{60}$ En DB: no 37, 6-Febrero-1856, p. 1.066.

${ }^{61}$ Con esta simbología hemos querido indicar nuestras dudas sobre la identidad del firmante.

62 "[...]Empézaremos [sic] por manifestar que si el representante del ministerio de la Guerra no estaba autorizado para resolver la parte militar del ensanche de Barcelona, ignoramos qué objeto pudo de tener su nombramiento; ni comprendemos tampoco el nombramiento de sus demás compañeros, no pudiendo partir de bases ciertas, pues que no es posible tratar con provecho del ensanche de Barcelona, sin haberse resuelto antes, de una manera absoluta y definitiva, si debe ó no ser plaza fuerte, y en caso afirmativo, cuál debe ser un sistema de defensas.

De todas maneras, las ideas emitidas por el representante del ministerio de la Guerra nos relevan el espíritu poco progresivo, escesivamente [sic] conservador del elemento militar en España. Lejos de nosotros el dar ascenso á los injustos cargos que se hacen á los cuerpos facultativos encargados principal é inmediatamente de la defensa del pais; para esplicar [sic] su inmovilidad, su espíritu de resistencia á toda innovación, no es necesario acudir como hace el vulgo á la gratuita y poco digna suposición de que obedecen á un sentimiento de dominacion y exclusivo, á un proposito de impedir el desarrollo del elemento industrial y comercial que consideran destinados á eclipsar su importancia en las sociedades modernas." En DB: nº 60-Febrero-1856, p. 1.751.

${ }^{63}$ En DB: no 54, 20-Febrero-1856, p. 1.481.
} 
cargada y aceras para peatones [sic], limitándose en él la construcción de las casas á segundo piso y á la mitad del terreno edificable, dejando la otra mitad para ventilación interior de las casas. Conforme Vds. conocerán, si la solución recaía [sic] favorable con arreglo al citado anteproyecto, la edificación se hacia completamente imposible, ó á lo menos muy difícil, porque en lugar de poder obligar á los dueños de los terrenos comprendidos dentro la zona del ensanche a concurrir al coste de la abertura de las grandes vías, es indudable que debiera indemnizárseles por el terreno que se ocuparía con ellas, ya que ninguna ventaja reportarían en el aumento del valor que pudiese recibir el terreno neutralizado con condiciones de tal suerte onerosas, que harían desaparecer todo interés particular, y por lo mismo la cuestión vendría á terminarse con la inevitable consecuencia de tener que pagar el gobierno el coste de las primeras vías, y Vds. comprenderán á lo que esto equivaldría." ${ }^{64}$

Una vez más, entre los mismos sostenedores de las cuatro vías del anteproyecto cerdiano: Camprodon, González y Masadas, surge el problema de definir quién deba costear las obras. La postura final parece concluir en la siguiente solución:

"[...]Las indicaciones apuntadas inclinaron pues á los tres citados individuos Campradon, Gonzales y Masadas, para que se accediese á la abertura de las cuatro vías, utilizando al efecto los intereses ya creados en las carreteras y paseos que parten del antiguo recinto, sin perjuicio de darles la latitud y alineaciones que reclama el ornato público y buen gobierno de toda población, con lo cual podría obligarse á los dueños de los terrenos y demás beneficiados con el ensanche á concurrir al coste de las obras necesarias para su apertura, sin otra limitación para la edificación, que la de regular, si se quiere, la altura de las casas á la de la latitud de la calle. Con esto se conciliaba lo practicable con la higiene y la belleza, el coste de la obra con las utilidades [sic] que reportarían los beneficiados con ella, y no se dejaría para un trazado en el papel una belleza imaginable, y una obra irrealizable por falta de medios."

Es de estas mismas fechas el último artículo del bienio liberal firmado por Mañé y Flaquer bajo el epígrafe "Fortificaciones de Barcelona".

Engendrado en las críticas conservadoras en contra del reciente derribo de las fortificaciones barcelonesas, Mañé, desde su postura progresista, se apoya en los casos europeos de París, Roma y Viena para avalar el "neo derribo" y el consiguiente ensanche ilimitado.

Una vez más, son los motines populares, y más detalladamente los recuerdos dejados por la revuelta liberal de julio de 1854 a minar el buen éxito del ensanche barcelonés.

Tras una breve reseña histórica sobre las murallas de la ciudad condal, Mañé se detiene en una meticulosa explicación estratégico-militar sobre la inutilidad de edificar unas nuevas murallas, sustituyéndolas, en caso extremo, con lo que el mismo autor define como "muro de seguridad":

"[...] A nuestro juicio, el ensanche de Barcelona debe ser ilimitado, y la población cerrada con un simple muro de seguridad, tapia aspilleraza [sic] y si se quiere flanqueada, por algunas torres aspillerazas [sic] también para la fusilería. Este muro, de insignificante costo y no sujeto á las reglas de la fortificación permanente, se podría ir alejando siempre que las necesidades de la población lo exigiesen.-Esto es lo que bastaría para evitar el contrabando é impedir las fechorías de una partida armada contra las extremidades [sic] de la ciudad." ${ }^{, 66}$

\footnotetext{
${ }^{64}$ En DB: $n^{\circ} 64,4-M a r z o-1856$, p. 1.863.

${ }^{65}$ En DB: $n^{\circ} 64,4-M a r z o-1856$, p. 1.863.

${ }^{66}$ En DB: $n^{\circ} 69,9-$ Marzo-1856, p. 2.019.
} 
Las nuevas fortificaciones, previstas por el cuerpo de ingenieros militares, implicarían, según Mañé, un gasto excesivo cuya magnitud, dadas las condiciones precarias del Estado, no podría ser absorbida por el desastrado Tesoro público.

Mañé se detiene también sobre el tema de los terrenos de las murallas reclamando, una vez más, su posesión por parte del Municipio y reconociéndolos como insuficientes para abarcar los gastos de expropiación para una eventual nueva fortificación.

Los últimos meses del bienio liberal marcan una nueva fase del caso barcelonés. Bajo los primeros desórdenes fabriles, dominados por el pulso firme del despótico Capitán general Juan Zapatero, un marco de incertidumbre y estancamiento parecen prevaler sobre una pronta actuación del ensanche barcelonés.

Utilizando una expresión de Antonio Brusi del año'53 el caso barcelonés parece, nuevamente, "sumergido en aparente letargo".

Derruidas las murallas, tal como nos demuestran los últimos artículos de Juan Mañé del año'56, el nuevo reto es el ensanche ilimitado.

Los antecedentes de la "malla infinita" ya están marcados, y con ella las primeras tensiones entre el gobierno local y su cultor: Ildefonso Cerdá , el ingeniero de caminos que obtendrá el 12 de enero de 1859, por parte del Ministerio de Fomento, la autorización para verificar los estudios de "ensanche y reforma" de Barcelona.

Concluido el bienio liberal, alejado Espartero de los escenarios políticos, inaugurada la etapa conservadora de Narváez, las nuevas coyunturas políticas y sociales marcarán el comienzo de una lenta actuación hacia el cumplimiento del binomio ensanche-plaza de guerra, ese mismo sintetizado por primera vez en las páginas del brusi en1853.

Con este trabajo puntual, engendrado en los escritos publicados en el Diario de Barcelona, hemos querido aportar una nueva visión sobre uno de los temas tal vez más estudiados: el ensanche de Barcelona.

Sin haber aportado algún dato inédito o de extraordinario valor, creemos, con esta investigación, haber introducido un nuevo personaje, un nuevo observador, en el más vasto y complejo escenario barcelonés de mediados del siglo XIX: Antonio Brusi, y con él los reflejos de las exigencias y de las preocupaciones de la segunda capital de España ante el tema crucial de su ensanche.

Quedando aún a definir muchos aspectos de indudable interés, como el ya citado empréstito propuesto por Pascual Madoz, los concisos datos recuperados durante este vaciado nos permiten proponerlos como ulteriores claves aclaradoras y de posible interés para otros investigadores ocupados en afinar sus conocimientos sobre el ensanche barcelonés durante el bienio liberal.

Quisiéramos concluir nuestra exposición agradeciendo el CPVS de la Universidad Politécnica de Cataluña que nos ha permitido desarrollar este trabajo, el Profesor Josep Roca Cladera, director del Departamento de Construcciones de la UPC y en especial modo el Profesor Javier García Bellido, director de la investigación, al que dedicamos el buen éxito de los datos recogidos durante estos meses, por toda la paciencia y atención con las que nos ha seguido, guiado, instruido, y que por desgracia nos ha dejado repentinamente hace poco. 